\title{
Synthesis of some substituted 1,3,4-oxadiazoles, thiadiazoles and 1,2,4-triazoles
}

\author{
Shereen R. Mohamed \\ Chemistry Department / College of Education \\ Dohuk University
}

Received

31 / 03 / 2008
Accepted

22 / $07 / 2008$

\begin{abstract}
الخلاصة

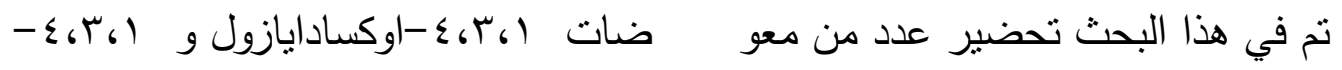

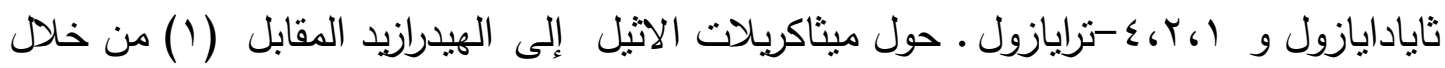
تفاعله مع الهيدرازين المائي في الايثنانول تم تحويل الهيدرازيد الى ثايوسيميكاربازيد المعوض

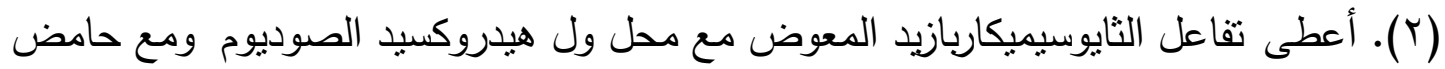

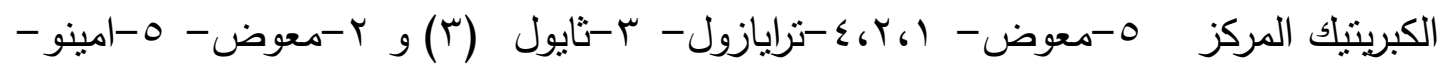

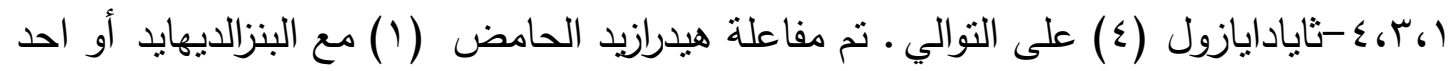

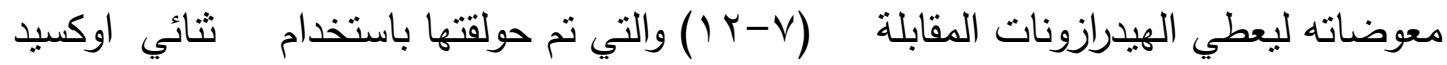

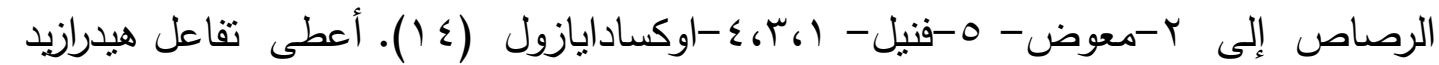

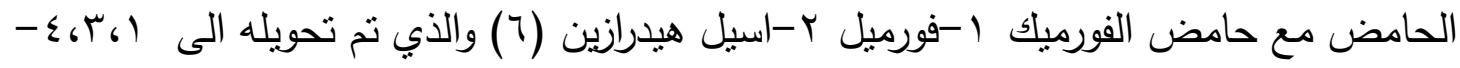
اوكسادايازول أحادي التعويض (T) (1) من خلال تفاعله مع خماسي اوكسيد الفسفور ـ تم مفاعلة .$(0)$

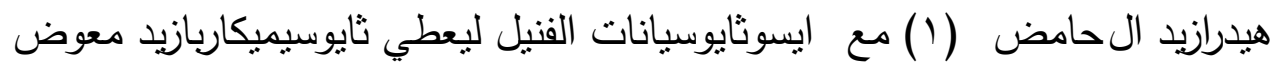

$$
\begin{aligned}
& \text { شخصت المركبات المحضرة بالطرق الفيزياوية والطيفية. }
\end{aligned}
$$

\section{ABSTRACT}

In this paper the synthesis of some substituted 1,3,4-oxadiazoles, 1,3,4-thiadiazoles and 1,2,4-triazoles is reported. Ethyl methacrylate was treated with hydrazine hydrate in ethanol to give the corresponding hydrazide (1). The hydrazide was converted to 1-acyl thiosemicarbazide (2) byits reaction with ammonium thiocyanate, which was treated with sodium hydroxide solution and with concentrated sulfuric acid to give 5substituted-1,2,4-triazoles-3-thiol (3) and 2-substituted-5-amino-1,3,4- 
thiadiazole (4) respectively. The acid hydrazide (1) was treated with benzaldehyde or substituted benzaldehyde to give hydrazones (7-12), the hydrazones were then cyclized with lead dioxide to 2-subtituted-5-phenyl 1,3,4-oxadiazole (14). The reaction of the hydrazide (1) with formic acid gave 1-formyl-2-acyl hydrazine (6) and the cyclization of (6) by phosphorus pentaoxide gave monosubstituted-1,3,4-oxadiazoles (13). Acid hydrazide (1) was treated with phenyl isothiocyanate to give substituted thiosemicarbazide (5).

The structure of the synthesized compounds were confirmed by physical and spectral means.

\section{INTRODUCTION}

1,3,4-oxidiazoles, 1,3,4-thiadiazoles and 1,2,4-triazoles and their derivatives are associated with various biological activities such as anticonvulsant $^{(1)}$, antifungal ${ }^{(2,3)}$, anticancer ${ }^{(4,5)}$, anti-inflammatory ${ }^{(6,7)}$ and antibacterial properties ${ }^{(8-10)}$. The therapeutic effect of these compounds have been well studies for a number of pathological cases including inflammation $^{(11)}$, pain $^{(12)}$ or hypertension ${ }^{(13)}$.

These biological data promoted many researchers to synthesized substituted 1,3,4-oxadiazole, 1,3,4-thiadiazole and 1,2,4-triazole by using a number of starting materials and methods. 1,3,4-Oxadiazoles were synthesized from acid hydrazides by their reaction with carbon disulfide in ethanolic potassium hydroxide ${ }^{(14,15)}$.

1,2-Diacyl hydrazine was treated with thionyl chloride to give substituted 1,3,4-oxdiazole, such as compound (I) ${ }^{(16)}$.

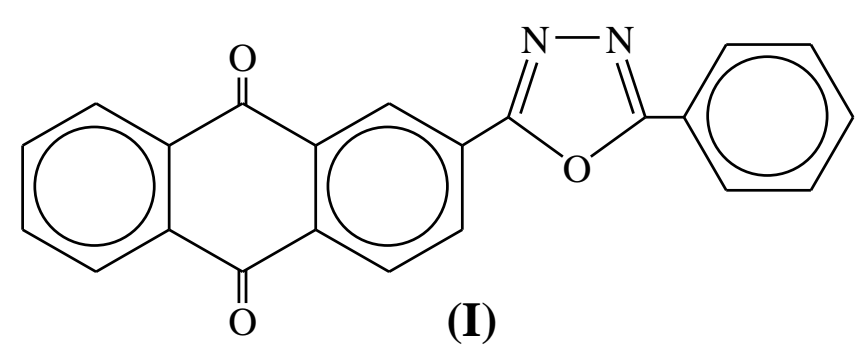

Whereas oxidation of substituted thiosemicarbazide with lead oxide $^{(17)}$ or potassium iodide/iodine ${ }^{(18)}$ gave substituted 1,3,4-oxadiazoles. Treatment of carboxylic acids with hydrazine in the presence of polyphosphoric acid gave 1,3,4-oxdiazolee as compound (II).

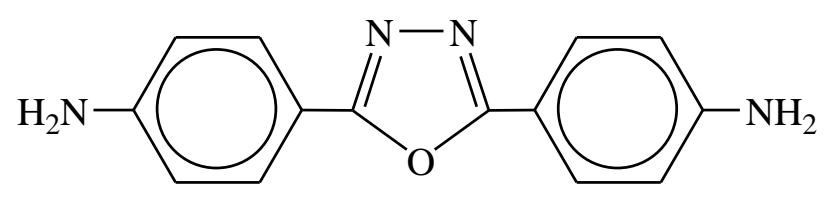

(II) 
Substituted 1,3,4-thiadiazoles were synthesized from substituted thiosemicarbazides by their reaction with concentrated sulfuric acid ${ }^{(19)}$ or methyl sulfonate ${ }^{(20)}$. Substituted 1,2,4-triazoles were synthesized from substituted thiosemicarbazide by its treatment with sodium hydroxide solution as the cconversion of (III) to (IV) ${ }^{(21)}$.
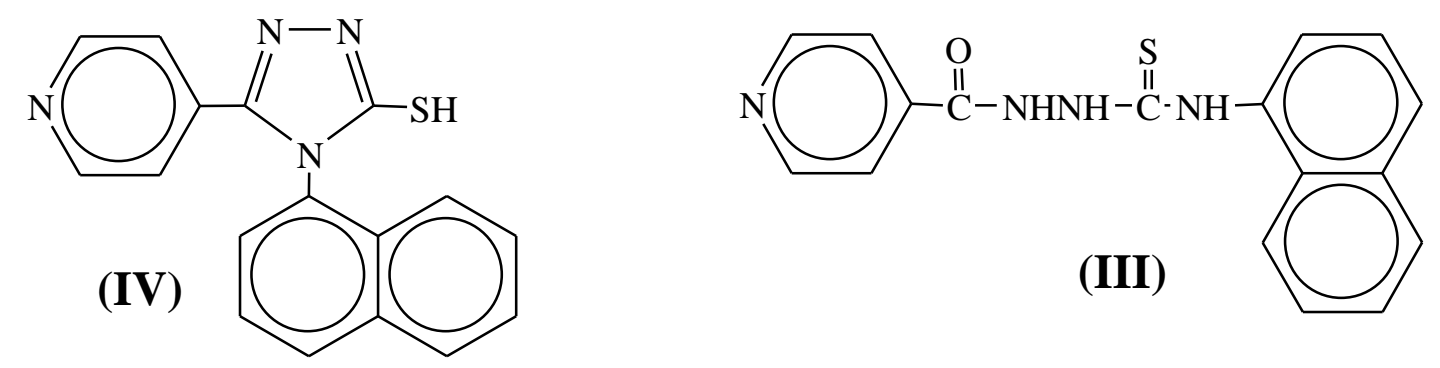

4-Amino-3,5-diphenyl-1,2,4-trizole was prepared by heating benzoic acid hydrazide to $\left(200^{\circ} \mathrm{C}\right)^{(22)}$.

In the present study some new 1,3,4-oxadiazoles, 1,3,4-thiadiazoles and 1,3,4-triazoles have been synthesized .

\section{EXPERIMENTAL}

The chemicals were purchased from Fluka and BDH chemical Ltd. The melting points were measured on an Electrothermal 9300 Engineering LTD and were uncorrected. IR spectra were recorded on Infrared Spectrophotometer Model Tensor 27, Bruker Co., using $\mathrm{KBr}$ discs. UV spectra were recorded on Shimadzu, UV-160, UV-Visible Recording Spectrophotometer.

\section{Methacrylic acid hydrazide (1)}

A mixture of ethyl methacrylate (5.68 g, 0.04 mole) and hydrazine hydrate $(0.2$ mole $)$ in absolute ethanol $(30 \mathrm{ml})$ was refluxed for 3 hours. The solvent was evaporated to give the hydrazide as a white powder, (Tables 1,2).

\section{1- Acyl thiosemicarbazide (2)}

A mixture of acid hydrazide (1) (1.44 g, 0.02 mole), ammonium thiocyanate (4.56 g, 0.06 mole), concentrated hydrochloric acid $(8 \mathrm{ml})$ in absolute ethanol $(50 \mathrm{ml})$ was refluxed for $22 \mathrm{hrs}$. The solvent was evaporated and residue poured on crushed ice with stirring. The solid materials which; formed was filtered off, dried and recrystallized from ethanol (Tables 1,2).

\section{5-(Propene-2-yl)-1,2,4-triazole-3-thiol (3)}

A mixture of substituted thiosemicarbazide (2) (1.59 g, 0.01 mole) and $2 \%$ aqueous sodium hydroxide solution $(15 \mathrm{ml})$ was refluxed for 3 
hrs. The mixture was treated with charcoal and the charcoal then removed by hot filtration, the filtrate was acidified by $10 \%$ hydrochloric acid with cooling. The precipitate was filtered and recrystallized from ethanol (Tables 1,2).

\section{2-(Propene-2-yl)-5-amino-1,3,4-thiadiazole (4)}

Concentrated sulfuric acid $(10 \mathrm{ml})$ was added to substituted thiosemicarbazide (2) (0.79 g, 0.05 mole). The mixture was heated on water bath $90^{\circ} \mathrm{C}$ with stirring for $2 \mathrm{hrs}$., the mixture then poured onto icewater and neutralized with concentrated ammonia solution with cooling, the formed precipitate was filtered washed with cold water, dried and recrystallized from benzene (Tale 1,2).

\section{1-(2-Methyl propenoyl)-4-phenyl thiosemicarbazide (5)}

A mixture of acid hydrazide (1) (1.44 g, 0.02 mole), phenyl isothiocyanate $(8.1 \mathrm{~g}, 0.06$ mole) and concentrated hydrochloric acid (8 mole) in ethanol $(50 \mathrm{ml})$ was refluxed for (10) hrs., the solvent was evaporated and the residue poured on crushed ice, the solid then filtered off, dried and recrystallized from ethanol (Tables 1,2).

\section{1-(2-methyl propenoyl)-2-formyl hydrazine (6)}

A mixture of acid hydrazide (1) $(0.72 \mathrm{~g}, 0.01 \mathrm{~mole})$ formic acid $(0.92 \mathrm{~g}, 0.02 \mathrm{~mole})$ in ethanol $(20 \mathrm{ml})$ was refluxed for $3 \mathrm{hrs}$. , the mixture was cooled and the solid filtered off dried and recrystallized from ethanol (Tables 1,2).

\section{Hydrazones (7-12)}

A mixture of benzaldehyde / substituted benzaldehyde ( 0.01 mole) and acid hydrazide (1) (0.72 g, 0.01 mole) in ethanol (20 mole) was refluxed for (2) hrs. The mixture was condensed and the precipitate was filtered and recrystallized from benzene (Tables 1,2).

\section{Cyclization of 1-(2-methyl propenoyl)-2-formyl hydrazine (6) to 2- (propene-2-yl)-1,3,4-oxadiazole (13)}

Phosphorous pentaoxide (1.42 g, 0.01 mole) was added to a solution of 1-formyl-2-acyl hydrazine (6) (0.01 mole) in dry xylene (40 $\mathrm{ml})$. The mixture was refluxed for $3 \mathrm{hrs}$., the solvent was evaporated and the residue washed with water, dried and crystallized from ethanol (Tables 1,2).

\section{Cyclization of the hydrazone (7) to substituted 1,3,4-oxadiazole (14)}

To a homogenous solution of hydrazones (7) $(0.01$ mole) in $20 \mathrm{ml}$ of glacial acetic acid, $\mathrm{PbO}_{2}(2.39 \mathrm{~g}, 0.01$ mole $)$ was added, the mixture 
then stirred with mechanical stirrer at $25^{\circ} \mathrm{C}$ for $1 \mathrm{hr}$. The reaction mixture was diluted with ice-water and left to stand for $24 \mathrm{hrs}$. The precipitate was filtered off and recrystallized from benzene (Tables 1,2).

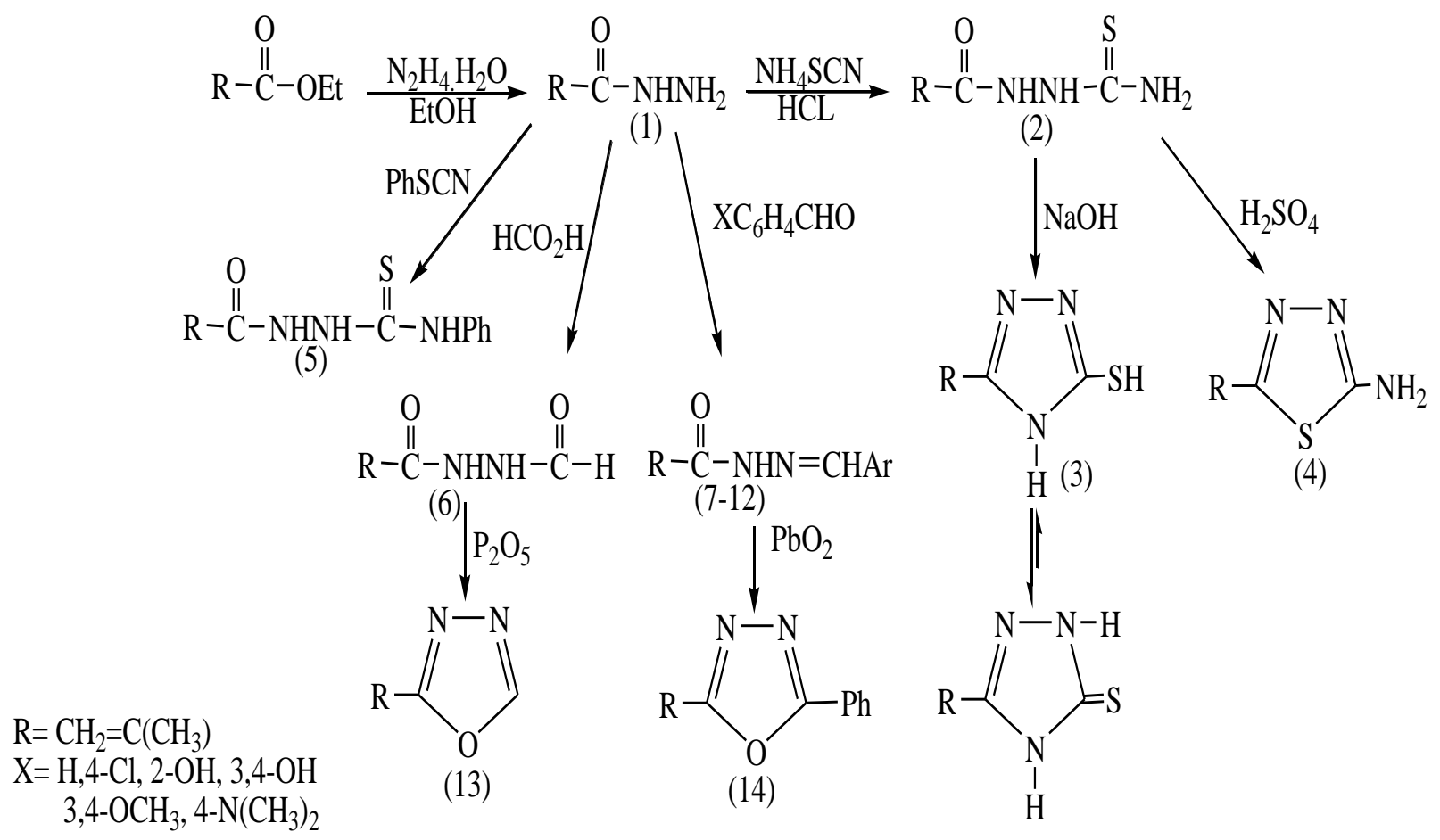

Scheme (1) 


\section{RESULTS AND DISUSSION}

In the paper the synthesis of mono and disubstituted 1,3,4oxadiazoles, 1,3,4-thiadiazoles and 1,2,4-triazoles from ethyl methacrylate is reported (Scheme 1). Ethyl methacrylate was treated with hydrazine hydrate in ethanol to give the acid hydrazide (1). Acid hydrazide (1) was treated with phenyl isothiocyanate to give substituted thiosemicarbazide (5), while treatment of acid hydrazide (1) with ammonium thiocyanate gave substituted thiosemicarbazide (2), treatment of thiosemicarbazide (2) with sodium hydroxide solution and with concentrated sulfuric aid gave 5-substituted-1,2,4-triazole-3-thiol (3) and 2-substituted-5-amino-1,3,4-thiadiazole (4) respectively.

The IR spectrum of compound (1) showed the following peaks $(\mathrm{v}$ $\left.\mathrm{cm}^{-1}\right) 3311(\mathrm{~N}-\mathrm{H}), 1654(\mathrm{C}=\mathrm{O}), 1605(\mathrm{C}=\mathrm{C})$; compound (2) $3355(\mathrm{~N}-\mathrm{H})$, $1676(\mathrm{C}=\mathrm{O}), 1608(\mathrm{C}=\mathrm{C}), 1285(\mathrm{C}=\mathrm{S})$, compound (3) $3380(\mathrm{~N}-\mathrm{H}), 1636$ $(\mathrm{C}=\mathrm{N}), 1609(\mathrm{C}=\mathrm{C}), 1150(\mathrm{C}=\mathrm{S})$; compound $(4), 3276(\mathrm{~N}-\mathrm{H}), 1637$ $(\mathrm{C}=\mathrm{N}), 1615(\mathrm{C}=\mathrm{C})$ and $1039(-\mathrm{S}-\mathrm{C})$, compound $(5) 3211(\mathrm{~N}-\mathrm{H}), 1660$ $(\mathrm{C}=\mathrm{O}), 1610(\mathrm{C}=\mathrm{C}), 1189(\mathrm{C}=\mathrm{S})$. hydrazide $(1)$ was treated with formic acid to give 1-(2-methyl propenoyl)-2-formyl hydrazine (6), compound (6) was cyclized by phosphorous pentaoxide to give 2-substituted-1,3,4oxadiazole (13) according to the following suggested mechanism:<smiles>[R]CN[NH2+][C@@H]([O-])[NH2+]NC([R])=O</smiles>

(13)

Treatment of compound (1) with benzaldehyde or substituted benzaldehyde gave hydrazones (7-12). The hydrazone (7) was treated with lead dioxide to give 2-(propene-2-yl)-5-phenyl-1,3,4-oxadiazole (14).

IR, v $\left(\mathrm{cm}^{-1}\right)$ for compound (6), $3445(\mathrm{~N}-\mathrm{H}), 1675(\mathrm{C}=\mathrm{O}), 1625$ $(\mathrm{C}=\mathrm{C})$; compound (7-12) 3422-3207 (N-H), 1688-1650 (C=O), 16241601 $(\mathrm{C}=\mathrm{C}), 1651-1632(\mathrm{C}=\mathrm{N})$, compound $(13), 1649(\mathrm{C}=\mathrm{N}), 1071(\mathrm{C}-\mathrm{O}-$ C); compound (14) $1628(\mathrm{C}=\mathrm{N}), 1600(\mathrm{C}=\mathrm{C}), 1072(\mathrm{C}-\mathrm{O}-\mathrm{C})$.

The ultraviolet spectra of the synthesised compound were recorded using chloroform as solvent and the $\lambda_{\max }$ data shown in Table (2).

The formation of substituted 1,3,4-thiadiazole and substituted 1,2,4-triazole may proceed through the mechanisms 1 and 2 respectively. 
<smiles>[R]C(=O)NN([NH])C(N)=S</smiles><smiles>[R]C1(O)CSCCN1NC(=[CH+])N</smiles><smiles>[R]c1nnc(N)s1</smiles><smiles>O=CO</smiles><smiles>[R]C1(O)SC(N)=NN1CC[CH2+]</smiles>

\section{Mechanism (1)}<smiles>[R]C(=O)NN1C(=S)NCCC1N</smiles><smiles>[R]C1([2H])NNC(=[SH]O)N1</smiles><smiles>[R]C1([R])NNC(=S)NN1</smiles><smiles>[R]c1nnc(SCC)[nH]1</smiles><smiles>[R]c1n[nH]c(=S)[nH]1</smiles><smiles>[R]C1(O)NNNC(=S)N1</smiles>

Mechanism (2) 
Table (1): Physical constants of compounds (1-14)

\begin{tabular}{|c|c|c|c|c|}
\hline Comp. No. & X & \%yield & m.p. $\left({ }^{\circ} \mathrm{C}\right)$ & Color \\
\hline 1 & $\cdot$ & 85 & $210-212$ & White \\
\hline 2 & $\cdot$ & 72 & $203-205$ & White \\
\hline 3 & $\cdot$ & 65 & $230-231$ & Gray \\
\hline 4 & $\cdot$ & 76 & $215-217$ & White \\
\hline 5 & $\cdot$ & 60 & $182-183$ & Green \\
\hline 6 & $\cdot$ & 44 & $149-151$ & White \\
\hline 7 & $\mathrm{H}$ & 57 & $122-123$ & Yellow \\
\hline 8 & $4-\mathrm{Cl}$ & 55 & $214-216$ & Yellow \\
\hline 9 & $2-\mathrm{OH}$ & 61 & $210-211$ & Pale yellow \\
\hline 10 & $3,4-\mathrm{OH}$ & 45 & $150-153$ & Brown \\
\hline 11 & $3,4-\mathrm{OCH}_{3}$ & 77 & $172-174$ & Pale yellow \\
\hline 12 & $4-\mathrm{NMe}_{2}$ & 53 & $166-167$ & Deep yellow \\
\hline 13 & $\cdot$ & 49 & $190-192$ & Pale green \\
\hline 14 & $\cdot$ & 56 & $>300$ & Pale brown \\
\hline
\end{tabular}

Table (2): Spectral data of compounds (1-14)

\begin{tabular}{|c|c|c|c|c|c|c|}
\hline \multirow{2}{*}{$\begin{array}{c}\text { Comp. } \\
\text { No. }\end{array}$} & \multicolumn{5}{|c|}{ IR $(\mathrm{KBr}) \mathrm{v} \mathrm{cm}^{-1}$} & \multirow{2}{*}{$\begin{array}{c}\mathrm{UV}, \mathrm{CHCl}_{3} \\
\lambda_{\max }(\mathrm{nm})\end{array}$} \\
\cline { 2 - 6 } & $\mathrm{C}=\mathrm{O}$ & $\mathrm{N}-\mathrm{H}$ & $\mathrm{C}=\mathrm{C}$ & $\mathrm{C}=\mathrm{N}$ & Others & 252 \\
\hline 1 & 1654 & 3311 & 1605 & $\cdot$ & $\cdot$ & 280 \\
\hline 2 & 1676 & 3355 & 1608 & $\cdot$ & $1285(\mathrm{C}=\mathrm{S})$ & 261 \\
\hline 3 & $\cdot$ & 3380 & 1609 & 1636 & $1150(\mathrm{C}=\mathrm{S})$ & 294 \\
\hline 4 & $\cdot$ & 3276 & 1615 & 1637 & $1039(\mathrm{C}-\mathrm{S}-\mathrm{C})$ & 255 \\
\hline 5 & 1660 & 3211 & 1610 & $\cdot$ & $1189(\mathrm{C}=\mathrm{S})$ & 247 \\
\hline 6 & 1675 & 3445 & 1625 & $\cdot$ & $\cdot$ & 297 \\
\hline 7 & 1660 & 3303 & 1624 & 1654 & $\cdot$ & 293 \\
\hline 8 & 1654 & 3413 & 1620 & 1632 & $\cdot$ & 294 \\
\hline 9 & 1688 & 3422 & 1619 & 1638 & $\cdot$ & 246 \\
\hline 10 & 1662 & 3387 & 1610 & 1642 & $\cdot$ & 293 \\
\hline 11 & 1600 & 3207 & 1602 & 1651 & $\cdot$ & 281 \\
\hline 12 & 1668 & 3420 & 1601 & 1646 & $\cdot$ & 244 \\
\hline 13 & $\cdot$ & $\cdot$ & $17 \cdot \wedge$ & 1649 & $1071(\mathrm{C}-\mathrm{O}-\mathrm{C})$ & 251 \\
\hline 14 & $\cdot$ & $\cdot$ & 1600 & 1628 & $1072(\mathrm{C}-\mathrm{O}-\mathrm{C})$ & 2 \\
\hline
\end{tabular}




\section{REFERENECS}

1. Kane J. M., Baron B. M., Dudley M. W., Sorensen S. M., Staeger M. A. and Miller F. P., J. Med. Chem., 33, 2772, (1990).

2. Rollas S., Kalyoncuoglu N., Sur-Altiner D. and Yegenoglu Y., Pharmazie, 48, 308, (1993).

3. Chollet J. F., Bonnemain J. L., Migiuniac L. and Rohr O. J., Pestic. Sci., 29, 427, (1990).

4. Holla B. S., Veerendra B., Shivanande M. K. and Poojary B., European Med. Chem., 38. 759, (2003).

5. Bekircan O., Kucuk M., Kahveci B. and Kolayli S., Arch. Pharm., 338, 365, (2005).

6. Wade P. C., Vogt B. R., Kissick T. P., Simpkins L. M., Palmer D. M. and Millomig R. C., J. Med. Chem., 25, 331, (1982).

7. Modzelewska B. and Kalabeeen, J. Pharmazie, 54, 503, (1999).

8. Malbec F., Milcent R., Vicart P. and Bure A. M., J. Heterocyclic Chem.., 21, 1769, (1984).

9. Milcent R., Vicart P. and Bure A. M., Eur. J. Med. Chim., 18, 215, (1983).

10.Gulerman N., Rollas S., Kiraz M., Ekinci A. C. and Vidin A., II Farmaco., 52, 691, (1997).

11.Palaska E., Sahim G., Kelicen P., Durlu N. T. and Altinok G., Farmaco., 57, 101, (2002).

12. Onkol T., Cokir B. and Sahin M. F., Turk. J. Chem., 28, 461, (2004).

13.Baldwin J. J., Engelhardt E. L., Hirschmann R., Ponticello G. S., Atkinson J. G., Wasson B., Sweet C. S. and Scriabine A., J. Med. Chem., 23, 65, (1980).

14. Amir M. and Shahani S., Indian j. Heterocccycli Chem., 8(2), 107, (1998).

15.El-Masry A. H., Fahmy H. H. and Abdulwahed S. H. A., Molecules, $5,1429,(2000)$.

16. Klingsberg E., J. Am. Chem. Soc., 5788, (1958).

17. Yousif K. H., Ph. D. Thesis, University of Mosul, (2000).

18. Hogal M. B. and Deshmukh D. J., Indian Chem. Soc., 66, 212, (1989).

19. Wu M. T., J. Heterocyclic Chem., 9, 31, (1972).

20. Kress T. J. and Costantino S. M., J. Heterocyclic Chem., 17, 607, (1980).

21. Zamani K., Faghihi K., Tofighi T. and Shariatzadeh M. R., Turk. J. Chem., 28, 91, (2004).

22. Shafiee A., Naimi E., Mansobi O., Foroumadi F. P. and Serkari M., J. Heterocyclic Chem., 32, 1235, (1995). 